\title{
The Association of Attachment Anxiety and Avoidance with Emotional Dating Abuse Perpetration Using Multimethod, Dyadic Data
}

\author{
Elizabeth A. Goncy \\ Cleveland State University, e.goncy@csuohio.edu \\ Manfred H.M. van Dulmen \\ Kent State University - Kent Campus, mvandul@kent.edu
}

Follow this and additional works at: https://engagedscholarship.csuohio.edu/clpsych_facpub

Part of the Clinical Psychology Commons, and the Counseling Psychology Commons How does access to this work benefit you? Let us know!

\section{Recommended Citation}

Goncy, Elizabeth A. and van Dulmen, Manfred H.M., "The Association of Attachment Anxiety and Avoidance with Emotional Dating Abuse Perpetration Using Multimethod, Dyadic Data" (2016). Psychology Faculty Publications. 21.

https://engagedscholarship.csuohio.edu/clpsych_facpub/21

This Article is brought to you for free and open access by the Psychology Department at EngagedScholarship@CSU. It has been accepted for inclusion in Psychology Faculty Publications by an authorized administrator of EngagedScholarship@CSU. For more information, please contact library.es@csuohio.edu. 


\title{
The Association of Attachment Anxiety and Avoidance With Emotional Dating Abuse Perpetration Using Multimethod, Dyadic Data
}

\author{
Elizabeth A. Goncy, PhD
}

\author{
Manfred H. M. van Dulmen, PhD
}

\begin{abstract}
This study examined the relationship between emotional dating abuse perpetration and attachment anxiety and avoidance using multimethod. multi-informant dyadic data. Data were derived from a sample of young adult heterosexual dating couples ( $N=113$ couples). We measured attachment through self-report survey data and emotional dating abuse through self-report surveys, partner-report surveys, and ratings by independent observers of a videotaped couple interaction. Both female and male anxiety were related to female emotional abuse across each method. Male anxiety was related to male emotional abuse in survey data, but female anxiety was related to male emotional abuse in observed data. Neither male nor female avoidance was related to emotional abuse. Dating abuse prevention should focus on attachment anxiety factors (e.g.. jealousy, anger) to reduce emotional abuse in young adult romantic relationships.
\end{abstract}

$\mathrm{E}$ motional dating abuse perpetration is prevalent in young adult romantic relationships with rates ranging between $60 \%$ and $90 \%$ at this age (Shorey, Cornelius, \& Bell, 2008). Understanding factors related to perpetration of emotional dating abuse, which includes acts such as making derogatory remarks toward one's partner, threatening him or her, and controlling or frequently monitoring behavior (Centers for Disease Control and Prevention [CDC], 2014), is important for reducing its negative effects. Emotional dating abuse occurs independently of and concurrently with physical dating abuse, with the consequences of emotional dating abuse often as damaging as those of physical aggression (Halpern, Oslak, Young, Martin. \& Kupper. 2001; O'Leary \& Smith Slep, 2003). Furthermore, it is related to higher rates of substance abuse (Shorey, Rhatigan, Fite, \& Stuart. 2011), internalizing problems (Shorey, Sherman, et al., 2011), and future physical dating abuse (Riggs \& O'Leary, 1996). As such, identifying factors (e.g., attachment) that may mitigate or exacerbate the impact 
of emotional dating abuse is important for prevention and intervention efforts for dating abuse.

\section{LINKING ATTACHMENT TO EMOTIONAL DATING ABUSE}

Attachment theory asserts that successful social and emotional development arises from experiences within the parent-infant relationship (Bowlby, 1973). Based on internalization of parental availability and responsiveness during these early experiences, individuals create internal working models which impact expectations of later relationship interactions (Sroufe \& Fleeson, 1986), including romantic attachment (Mikulincer \& Shaver, 2007). Children whose parents provided consistent security and responsiveness are described as having a secure attachment style, whereas children from insensitive and unresponsive parents are classified as insecure (i.e., anxious, avoidant). Because the transfer of attachment from parents to romantic partners occurs during one's late teens and early 20s (Fraley \& Davis, 1997), young adulthood is an ideal time to investigate the role of attachment in romantic relationships.

Anxious attachment involves unhealthy obsession and preoccupation with the relationship. extreme jealousy, and fear of abandonment and rejection (Brennan, Clark, \& Shaver, 1998). Individuals with attachment anxiety are described as needy, demanding, and dependent within romantic relationships with frequent fear of partner loss. They are also more likely to display an exaggerated response to relationship difficulties (Mikulincer \& Florian, 1998) or to have an angry temperament (Follingstad, Bradley, Helff, \& Laughlin. 2002). These characteristics may lead to amplified emotions, higher distress, and greater use of negative conflict resolution strategies during romantic conflict (Campbell. Simpson, Boldry, \& Kashy, 2005). Heightened anger and fear of relationship dissolution may lead to use of emotional abuse to control one's partner and the relationship (Dutton, Saunders, Starzomski, \& Bartholomew, 1994). On the other hand. attachment avoidance involves the evasion of romantic intimacy and discomfort with closeness (Brennan et al., 1998). This style is often related to a belief that others are unreliable and mistrustful, with a tendency to rely on one's self rather than a romantic partner. Individuals with higher avoidance are more likely to suppress negative emotions or avoid conflict within their relationships (Mikulincer \& Florian, 1998). This pattern may result in a partner engaging in more emotional abuse toward an individual with high avoidance.

The preponderance of evidence linking insecure attachment to dating abuse has focused on physical abuse perpetration and victimization (e.g., Bookwala \& Zdaniuk, 1998; Kuijpers, van der Knaap, \& Winkel, 2012; Lawson \& Brossart. 2009), with increasing interest in emotional dating abuse perpetration in recent years (e.g., Lawson \& Malnar, 2011; Turner \& Langhinrichsen-Rohling, 2011). In general, this evidence suggests individuals in more physically or emotionally aggressive relationships report more insecure attachment. For example, insecurely attached individuals often have difficulties in developing adaptive conflict resolution strategies and may resort to using emotional abuse during romantic conflict (Shulman, 2003). Across these studies, evidence is mixed regarding the relationship between attachment and emotional dating abuse perpetration, with some studies suggesting higher attachment anxiety (e.g., Lawson \& Brossart, 2009; Orcutt, Garcia. \& Pickett, 2005), higher attachment avoidance (e.g.. Kuijpers et al.. 2012; Lawson \& Malnar, 2011), or both (e.g., Turner \& Langhinrichsen-Rohling, 2011) related to emotional dating abuse. 
Furthermore, dating a partner with an insecure attachment style is related to emotional dating abuse perpetration. For example, in a sample of college students, attachment anxiety predicted higher rates of both self-perpetrated and partner-perpetrated emotional dating abuse after controlling for gender, physical dating abuse, relationship length, and depressive symptoms (Riggs \& Kaminski, 2010). In another sample of dating young adults, the partner's attachment anxiety predicted perpetration of verbal dating abuse (Miga, Hare, Allen, \& Manning, 2010). Other studies have investigated the combination of attachment styles within the relationship. Kesner and McKenry (1998) concluded that both male and female insecure attachment predicted male perpetration of physical abuse in long-term married and cohabiting couples. Using a community sample of 70 young adult couples, Doumas, Pearson. Elgin. and McKinley (2008) reported that male and female physical abuse perpetration was highest in couples with high male attachment avoidance and high female attachment anxiety. Similarly, Bond and Bond (2004) concluded that the same combination of an anxious female partner and avoidant male partner predicted higher physical aggression use and nonphysical intimidation in couples attending relationship counseling. Lafontaine and Lussier (2005) replicated these results in a larger sample of married or cohabiting couples and found that male avoidance of intimacy and female anxiety over abandonment were both correlated with higher rates of emotional abuse perpetration and victimization.

\section{LIMITATIONS OF PREVIOUS RESEARCH}

Despite evidence linking emotional dating abuse and insecure attachment, these studies have been limited in important ways. First, most of these studies relied on singleinformant designs with few exceptions (Bond \& Bond, 2004; Doumas et al., 2008; Kesner \& McKenry, 1998; Miga et al., 2010). However, the studies with dyadic data were not without limits. For example, both Miga et al. (2010) and Kesner and McKenry (1998) lost unique, individual contributions by summing scores from females and males in their analyses. In efforts to avoid underreporting biases, Doumas et al. (2008) used the higher abuse score, whereas Lafontaine and Lussier (2005) used the victim's report. In all cases, unique information representing the dyadic interaction was not included. The processes and interactions within romantic relationships are best understood by incorporating information from both individuals through a dyadic design.

In addition, all studies relied on self-report questionnaires of emotional dating abuse, which have many disadvantages including social desirability, questionable accuracy, and distorted recall (Rathus \& Feindler, 2004). Furthermore, insecurely attached individuals often misreport their own, particularly negative, behavior (Berger. Jodl. Allen, McElhaney, \& Kuperminc, 2005); thus, they may minimize emotional dating abuse within self-reports. Research also demonstrates that both males and females likely underreport their own use of dating abuse (e.g.. Riggs \& Kaminski, 2010). As a result, many studies dichotomize abuse measures to compare relationships reporting abuse to those without (e.g.. Bond \& Bond, 2004; Kesner \& McKenry, 1998). Emotional dating abuse, therefore, may require measurement different from self-report surveys.

Analogue observations provide many advantages over self-report, survey methodology, specifically because they are more objective and less subjective to perceptual biases (Heyman, 2001). Direct observation of dyadic interactions permits assessment of romantic behavior and dating abuse in a controlled environment where intense exchanges can 
be primed to occur (Margolin et al., 1998). Although criticized for lacking ecological validity, research generally demonstrates external validity of analogue observations in matching at-home behavior (e.g.. Heyman, 2001). Observations of couple interactions may also provide information not captured by self-report methodology. For example. observationally assessed emotional dating abuse predicted romantic relationship satisfaction above and beyond self-reported emotional dating abuse (van Dulmen. Mata, \& Klipfel, 2012).

\section{GOALS OF PRESENT STUDY}

This study will examine the link between emotional dating abuse perpetration and attachment anxiety and avoidance using multimethod, multi-informant dyadic data. Multimethod, multi-informant data will increase the reliability of results by demonstrating whether associations between behaviors occur because of shared methodology. We focus on emotional dating abuse because it is more common than physical abuse (Shorey et al., 2008), often co-occurs with and predicts physical abuse (Halpern et al., 2001; O’Leary \& Smith Slep, 2003; Riggs \& O'Leary, 1996), and is less studied than physical abuse. Based on previous research, we offer the following hypotheses: (1) Greater male and female attachment anxiety will be related to higher emotional dating abuse for both females and males, (2) greater male and female attachment avoidance will be related to higher emotional dating abuse for both females and males, and (3) these relationships will be replicated across self-reported. partner-reported, and observed emotional dating abuse perpetration.

\section{METHOD}

\section{Participants and Procedures}

Dating nonmarried couples $(N=120)$ were recruited through a psychology subject pool at a large Midwestern state university. Eligibility criteria included involvement in a romantic relationship for at least 4 months and one member of the dyad being a student. Couples participated in a multimethod, multi-informant longitudinal study of romantic relationships during late adolescence and young adulthood (van Dulmen \& Goncy, 2010). Dyads completed an in-lab Wave 1 assessment including paper-and-pencil questionnaire packets and a dyadic observational assessment. During this videotaped observational assessment, couples completed three tasks: a conflict resolution task that provided couples with 10 minutes to solve an agreed-upon salient issue in their relationship (MarkhamCox, 1991), a 4-minute cooldown task to discuss topics that were not an issue for the couple. and a 10 minutes to plan a fictitious all-expenses-paid weekend getaway (Cooper \& Grotevant, 1987). The final sample ( $n=113$ couples) excluded homosexual couples ( $n=4$ couples) and couples whose videotaped observations could not be coded because of technical difficulties ( $n=3$ couples). Over half of the couples (52\%) reported involvement in the current relationship for 12 months or longer, with six couples cohabiting. Males and females were predominantly White $(89 \%, 88 \%$ respectively). More females $(99 \%)$ were currently attending school than males $(82 \%)$. Females $(M=19.13$ years, $S D=0.80)$, on average, were younger $(p<.001)$ than males $(M=20.25$ years, $S D=1.80)$. This study was approved by the IRB of the authors' universities. 


\section{Measures}

Attachment. The Experiences in Close Relationships Scale-Revised (Fraley, Waller, \& Brennan. 2000) measured attachment anxiety (e.g.. I often worry that my partner will not want to stay with me) and attachment avoidance (e.g.. I get uncomfortable when a romantic partner wants to be very close) through 36 items measured on a 7-point Likert scale. Higher scores represent higher anxiety or avoidance. Previous research demonstrated good reliability and validity for both subscales (Fraley et al., 2000). In this study, Cronbach's alphas for both the anxiety and avoidance scales were good for both females $(\alpha=.94$, $\alpha=.92)$ and males $(\alpha=.91, \alpha=.90)$.

Emotional Abuse. Participants completed the Conflict in Adolescent Dating Relationships Inventory (CADRI; Wolfe et al., 2001), which measures several forms of dating abuse. This article only used the 10 -item emotional and verbal abuse perpetration scale. Items are rated on a 4-point Likert scale, $1=$ never, $2=$ seldom (happened only about 1-2 times), $3=$ sometimes (happened about 3-5 times), $4=$ often (happened 6 or more times). Previous research demonstrated good reliability and validity for this subscale (Wolfe et al., 2001). Each participant also completed the same measure reporting on their partner's behavior. Internal consistency was good for female report of their own emotional dating abuse $(\alpha=.88)$ and their partner's emotional dating abuse $(\alpha=.89)$, as well as for male report of their own emotional dating abuse $(\alpha=.88)$ and their partner's emotional dating abuse $(\alpha=.90)$. We chose to use the CADRI because its items are more developmentally appropriate for late adolescent and young adult samples (i.e., 18- and 19-year-old couples) compared to measures created for adult or marital relationships. Furthermore, the CADRI has been successfully used in similar, early college samples (e.g.. Roudsari, Leahy, \& Walters, 2009; Simon, Kobielski, \& Martin, 2008).

Four items (blaming him or her for a problem, insulting him or her with put-downs, saying something to make him or her angry, and bringing up something bad that he or she did in the past) derived from the emotional abuse scale of the CADRI created a composite score of observed emotional dating abuse. Three items (threatened to end the relationship, ridiculed or made fun of him or her in front of others, and kept track of who she or he was with and where she or he was) were not coded because of a high likelihood they would not occur during the observation. A fourth item (spoke to him or her in a hostile or mean tone of voice) was not coded because of the potentially subjective nature of the item. Although the remaining two items were coded (did something to make him or her feel jealous, accused him or her of flirting with another girl or boy), the low frequency and lack of variability of these codes ( $M=1.05, S D=0.31, M=1.06, S D=0.23$, respectively) negatively impacted the internal consistency of the scale and thus were not included in the final score.

Coding was completed by trained undergraduate and graduate student research assistants who coded tapes for both female and male use of emotional abuse across the entire observation (i.e., all three previously described tasks). All coders were blind to the selfreport measures. Using the same 4-point Likert scale as the self-report measure, these items were rated by coders from the videotaped observational assessments. Interrater reliability (intraclass correlations) were as follows: said something to make partner angry, $r=$ .59 ; insulting, $r=.76$; brought up past, $r=.78$; and blaming, $r=.81$. All observations were coded by at least two individuals. Because some of the interrate reliabilities were low and likely attributable to the subjective nature of these behaviors, disagreements between coders were resolved through consensus coding in group meetings with all other coders. 


\section{Analysis Plan}

We first calculated descriptive statistics, including mean differences between genders and bivariate correlations across attachment anxiety, attachment avoidance, and self-reported. partner-reported. and observationally assessed emotional dating abuse perpetration (hereafter, referred to as anxiety, avoidance, and emotional abuse, respectively). One way to model multimethod. multi-informant dyadic data is to implement the actor-partner interdependence model (APIM; Kenny, Kashy, \& Cook, 2006). The APIM was designed to incorporate dyadic data and handle the interdependent data of couples (Kenny, 1996). More important, the APIM technique helps disentangle individual and dyadic level effects and distinguishes contributions from individuals or the couple using path analysis. For example, the model can specify whether emotional abuse is related to one's own attachment (actor effect), one's partner's attachment (partner effect), or to both one's own and one's partner's attachment (couple effect). We followed procedures outlined by van Dulmen and Goncy (2010) to test the hypotheses using the APIM technique in a multimethod, multi-informant framework. We incorporated multiple actor and partner paths from attachment (i.e., attachment anxiety and attachment avoidance) to (a) self-reported, (b) partner-reported, and (c) observed emotional abuse (see Figure 1). These analyses were conducted in Mplus 7.11 (Muthén \& Muthén, 2014).

We initially tested a measurement model to determine the impact of nonindependence from the dyadic data. This involved comparing a model with no equality constraints to a model with equality constraints on the correlations between females and males to account for nonindependence of dyadic data in self-reported measures (see dashed lines in Figure 1). In other words, we correlated female and male anxiety, female and male avoidance, and self-reported female and male emotional abuse. To test model fit, change in chi square was examined. If the difference is nonsignificant, we can assume that the amount of nonindependence was similar across self-report measures and should be accounted for in subsequent analyses. After testing this assumption, the model presented in Figure 1 was analyzed to answer Hypothesis 1 and 2. To test Hypothesis 3, we conducted subsequent

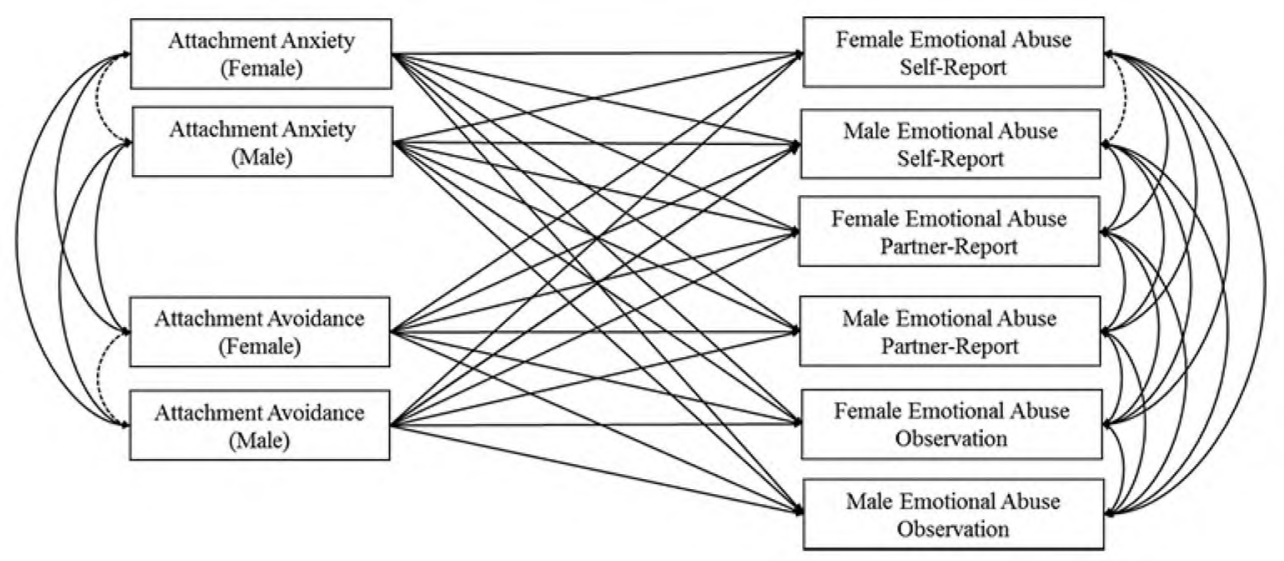

Figure 1. Actor-partner interdependence model for attachment anxiety, attachment avoidance, and self-report, partner-report, and observed emotional abuse perpetration. Dotted lines within correlations indicate where equality constraints were placed to account for nonindependence of dyadic data. 
analyses to test whether actor or partner effects were stronger for one methodology (i.e., self-report. partner-report. and observation). In each model. we placed equality constraints on the following paths representing both actor and partner effects in four separate models for females: (a) female anxiety with self-reported, partner-reported, and observed female emotional abuse (actor effects for anxiety and emotional abuse); (b) male anxiety with self-reported. partner-reported. and observed female emotional abuse (partner effects for anxiety and emotional abuse); (c) female avoidance with self-reported, partner-reported. and observed female emotional abuse (actor effects for avoidance and emotional abuse); and (d) male avoidance with self-reported. partner-reported, and observed female emotional abuse (partner effects for avoidance and emotional abuse). These same constraints were then tested for males. These analyses indicate whether the magnitude of the effects between attachment and emotional abuse is similar across self-report, partner-report. and observed emotional abuse. A statistically significant chi-square difference indicates that the effects were statistically different from each other and stronger for one method. whereas a nonstatistically significant chi-square difference indicates no differences between the methods.

\section{RESULTS}

\section{Descriptive Statistics and Bivariate Correlations}

Descriptive statistics and bivariate correlations for all study variables are presented in Table 1 for individual scales. On average, females and males did not differ in their report of anxiety or avoidance. Self-reported anxiety was higher than self- and partner-reported avoidance for both females ( $d=.40$ and .47 , respectively) and males $(d=.41$ and .34 . respectively). Most individuals reported some emotional abuse perpetration. In fact, $96.5 \%$ of females and $91.9 \%$ of males reported engaging in at least one act of emotional abuse toward their partner in the past year.

Gender Differences in Emotional Abuse. For females, self-reported emotional abuse was higher compared to partner-reported emotional abuse $(d=.11)$, but females were observed using more emotional abuse compared to either self- or partner-report ( $d=.34$ and .46, respectively). For males, partner-reported emotional abuse was higher compared to self-reported emotional abuse $(d=.11)$, but there were no differences between self- or partner-reported emotional abuse with observed emotional abuse. Females perpetrated more emotional abuse than males in both self-report $(d=.23)$ and observationally assessed emotional abuse $(d=.41)$ but not in partner-reports. All other mean differences were not statistically significant.

Attachment and Emotional Abuse. Female anxiety, female avoidance, male anxiety, and male avoidance correlated significantly with each other. Self-reported, partnerreported, and observed female and male emotional abuse were also significantly correlated with correlations by gender higher across survey-reports (i.e., self- and partner-report) than across methods (i.e., either survey report with observed emotional abuse). Female anxiety significantly correlated with all measures of female emotional abuse but only observed male emotional abuse. Female avoidance significantly correlated with self- and partner-reported but not observed female emotional abuse or any measure of male emotional abuse. Male anxiety significantly correlated with self- and partner-reported but not observed male emotional abuse and all measures of female emotional abuse. Male avoidance significantly correlated with partner-reported but not self-reported or observed male 
TABLE 1. Bivariate Correlations, Means, and Standard Deviations of Attachment and Emotional Dating Abuse

\begin{tabular}{|c|c|c|c|c|c|c|c|c|c|c|}
\hline & 1 & 2 & 3 & 4 & 5 & 6 & 7 & 8 & 9 & 10 \\
\hline \multicolumn{11}{|c|}{ Attachment } \\
\hline 1. Female anxiety & - & $.19 *$ & $.54 * *$ & $.38 * *$ & $.40 * *$ & -.03 & $.37 * *$ & .05 & $.30 * *$ & $.26 * *$ \\
\hline 2. Male anxiety & & - & $.34 * *$ & $.52 * *$ & $.29 * *$ & $.38 * *$ & $.30 * *$ & $.38 * *$ & $.21 *$ & .11 \\
\hline 3. Female avoidance & & & - & $.39 * *$ & $.21 * *$ & .01 & $.20^{*}$ & .07 & .17 & .17 \\
\hline 4. Male avoidance & & & & - & $.25 * *$ & .12 & $.22 *$ & $.22 *$ & $.24 *$ & .13 \\
\hline \multicolumn{11}{|c|}{ Emotional Dating Abuse } \\
\hline \multicolumn{11}{|l|}{ Self-report } \\
\hline 5. Female & & & & & - & $.54 * *$ & $.93 * *$ & $.62 * *$ & $.33 * *$ & $.28 * *$ \\
\hline 6. Male & & & & & & - & $.58 * *$ & $.92 * *$ & $.33 * *$ & $.30 * *$ \\
\hline \multicolumn{11}{|l|}{ Partner-report } \\
\hline 7. Female & & & & & & & - & $.65 * *$ & $.36 * *$ & $.29 * *$ \\
\hline 8. Male & & & & & & & & - & $.40 * *$ & $.30 * *$ \\
\hline \multicolumn{11}{|l|}{ Observed } \\
\hline 9. Female & & & & & & & & & - & $.56^{* *}$ \\
\hline 10. Male & & & & & & & & & & - \\
\hline$M^{\mathrm{a}}$ & 2.58 & 2.61 & 2.14 & 2.22 & 1.92 & 1.78 & 1.85 & 1.85 & 2.12 & 1.88 \\
\hline$S D$ & 1.22 & 1.02 & 0.98 & 0.88 & 0.60 & 0.63 & 0.59 & 0.70 & 0.58 & 0.61 \\
\hline Range & $1.0-6.8$ & $1.0-5.6$ & $1.0-5.6$ & $1.0-5.1$ & $1.0-3.6$ & $1.0-3.5$ & $1.0-3.5$ & $1.0-3.5$ & $1.0-3.5$ & $1.0-3.5$ \\
\hline$\alpha$ & .94 & .91 & .92 & .90 & .88 & .88 & .90 & .89 & - & - \\
\hline
\end{tabular}

all means are based on the Likert-scale response options and do not represent exact frequencies.

$* p<.05 . * * p<.01$. 
emotional abuse. However, male avoidance significantly correlated with all three measures of female emotional abuse.

\section{Test of Nonindependence}

Based on the assumption of nonindependence of dyadic data across self-report survey measures, we examined the impact of this assumption in a measurement model. We calculated the difference in the chi square of model fit of the model with no equality constraints $\left(\chi^{2}[24]=69.60, p<.001\right)$ to a model including equality constraints (see Figure 1$)$ on the correlations between female and male attachment anxiety, female and male attachment avoidance, and female and male self-reported emotional abuse $\left(\chi^{2}[26]=71.77, p<.001\right)$. Because the difference $\left(\Delta \chi^{2}[2]=2.17, p=.338\right)$ was nonsignificant, we operated on the assumption of nonindependence. This means that the amount of nonindependence because of dyadic data was similar across self-report measures. Thus, the equality constraints were maintained in the subsequent models.

\section{Hypotheses 1 and 2}

Hypotheses 1 and 2 stated that both greater male and female anxiety (Hypothesis 1) and avoidance (Hypothesis 2) would be related to higher emotional abuse for both females and males. The results of the overall model from Figure 1 are presented in Table 2 . The fit indices for this model demonstrated an excellent fit. $\chi^{2}(2)=3.45, p=.178$, CFI $=.99$. TLI $=.95$, RMSEA $=.08$. This model explained $19 \%, 18 \%$, and $11 \%$ of the variance in self-reported, partner-reported, and observationally assessed female emotional abuse, respectively. This model also explained $15 \%, 13 \%$, and $7 \%$ of the variance in self-reported. partner-reported, and observed male emotional abuse, respectively. Overall. Hypothesis 1 was partially supported for anxiety with no support for Hypothesis 2 (avoidance).

Self-Reported Emotional Abuse. Both female and male anxiety, but neither female nor male avoidance, was related to higher female emotional abuse, indicating a couple effect between anxiety and self-reported female emotional abuse. Only male anxiety, but not male avoidance, female anxiety, or female avoidance, was related to higher male emotional abuse (actor effect between male anxiety and male emotional abuse).

Partner-Reported Emotional Abuse. Both greater female and male anxiety, but neither female nor male avoidance, was related to higher female emotional abuse. This indicated a couple effect between anxiety and partner-reported female emotional abuse. Only male anxiety, but not male avoidance, female anxiety, or female avoidance, was related to higher partner-reported male emotional abuse (actor effect between male anxiety and male emotional abuse).

Observed Emotional Abuse. Only female anxiety, but not female avoidance, male anxiety, or male avoidance, was related to higher observed female emotional abuse (actor effect for female anxiety and observed female emotional abuse). Only female anxiety, but not male anxiety, nor female or male avoidance, was related to greater observed male emotional abuse. This represented a partner effect for female anxiety and observed male emotional abuse and was not consistent with the findings from the self- and partnerreported survey data, which indicated actor effects.

\section{Hypothesis 3}

We also investigated whether effects of attachment on emotional abuse differed based on the method of reporting emotional abuse (i.e., self-report, partner-report, and observational 
TABLE 2. Standardized Estimates for Path Analyses Between Attachment and Emotional Dating Abuse

\begin{tabular}{|c|c|c|c|c|c|c|c|c|c|c|c|c|}
\hline \multirow[b]{4}{*}{ Attachment } & \multicolumn{12}{|c|}{ Emotional Dating Abuse } \\
\hline & \multicolumn{4}{|c|}{ Self-Report } & \multicolumn{4}{|c|}{ Partner-Report } & \multicolumn{4}{|c|}{ Observed } \\
\hline & \multicolumn{2}{|c|}{ Female } & \multicolumn{2}{|c|}{ Male } & \multicolumn{2}{|c|}{ Female } & \multicolumn{2}{|c|}{ Male } & \multicolumn{2}{|c|}{ Female } & \multicolumn{2}{|c|}{ Male } \\
\hline & $\beta$ & $S E$ & $\beta$ & $S E$ & $\beta$ & $S E$ & $\beta$ & $S E$ & $\beta$ & $S E$ & $\beta$ & $S E$ \\
\hline Female anxiety & $.37 * * *$ & .10 & -.04 & .10 & $.35 * * *$ & .10 & .00 & .11 & $.26^{*}$ & .10 & $.23 *$ & .11 \\
\hline Male anxiety & $.23 *$ & .10 & $.42 * * *$ & .10 & $.26^{*}$ & .10 & $.36^{* * * *}$ & .10 & .13 & .10 & .06 & .11 \\
\hline Female avoidance & -.08 & .10 & -.08 & .11 & -.08 & .10 & -.07 & .11 & -.05 & .11 & .02 & .11 \\
\hline Male avoidance & .01 & .10 & -.06 & .11 & -.03 & .10 & .04 & .11 & .09 & .11 & -.01 & .11 \\
\hline
\end{tabular}

Note. Model fit is $\chi^{2}(2)=3.45, p=.18, \mathrm{CFI}=.99, \mathrm{TLI}=.95, \mathrm{RMSEA}=.08$.

$* p<.05 . * * * p<.001$. 
data). All subsequent models were compared to the initial model chi square, $\chi^{2}(2)=3.45$. Overall, this hypothesis, that the relationships between attachment and emotional abuse would be replicated across methodologies, was partially supported.

For anxiety and emotional abuse, chi-square differences tests indicated that there were no difference in the magnitude of the relations between self-reported. partner-reported. and observed female emotional abuse for either female anxiety $\left(\Delta \chi^{2}|2|=0.95, p=.622\right.$, actor effects) or male anxiety $\left(\Delta \chi^{2}[2]=1.48, p=.477\right.$, partner effects $)$. However, for males, differences in the magnitudes between self-reported. partner-reported, and observed male emotional abuse existed for male anxiety $\left(\Delta \chi^{2}[2]=9.60, p=.008\right.$, actor effects $)$ and trended for female anxiety $\left(\Delta \chi^{2}[2]=5.53, p=.063\right.$, partner effects). Closer examination suggested that the actor effects were stronger for self-reported and partner-reported male emotional abuse than for observed emotional abuse, whereas the partner effects were stronger for observed male emotional abuse than self-reported or partner-reported male emotional abuse.

For avoidance and emotional abuse, there was no difference in the magnitude of the relations between self-reported. partner-reported, and observed female emotional abuse for either female avoidance $\left(\Delta \chi^{2}[2]=0.07, p=.968\right.$, actor effects) or male avoidance $\left(\Delta \chi^{2}[2]=1.84, p=.399\right.$, partner effects $)$. A trend emerged for the relations of male avoidance with male emotional abuse $\left(\Delta \chi^{2}[2]=568, p=.058\right.$, actor effects); however, differences in the magnitudes between self-reported, partner-reported, and observed male emotional abuse did not exist for female avoidance $\left(\Delta \chi^{2}[2]=0.80, p=.670\right.$, partner effects).

\section{DISCUSSION}

The goal of this study was to examine the relationship between romantic attachment anxiety and avoidance with emotional dating abuse using multimethod, multi-informant dyadic data. We extended previous research by incorporating multi-informant, multimethod data to an area previously examined with mainly survey, self-report data. This study also extended previous research on emotional abuse by concurrently examining the relation of both attachment anxiety and avoidance to emotional dating abuse perpetration within young adult romantic relationships. Specifically, this study extended previous research on emotional abuse (i.e., Miga et al., 2010; Riggs \& Kaminski, 2010) by demonstrating that higher levels of attachment anxiety, but not attachment avoidance, predicted higher rates of emotional abuse within young adult romantic relationships for both females and males.

The relationship between attachment anxiety and emotional abuse illustrated an interesting story that varied by gender. As expected, for both self-reported and partner-reported female emotional abuse, both female and male anxiety related to higher female emotional abuse, demonstrate a couple effect. Only female anxiety was related to observed female emotional abuse. Post hoc analyses suggest that the magnitude of the partner effect, between observed female emotional abuse and attachment anxiety, was of a similar size as the self- and partner-reported emotional abuse. Subsequently, the conclusion is that our findings indicate that both female and male attachment anxiety are related to female use of emotional abuse in dating relationships. This replicates and extends previous research (e.g., Bond \& Bond. 2004; Doumas et al., 2008) demonstrating the relationship between female anxiety and female use of emotional abuse and extends these findings 
by demonstrating the unique association after consideration of male anxiety, attachment avoidance, and male use of emotional abuse.

For males, their own level of attachment anxiety, but not their partner's, is related to higher self-reported or partner-reported emotional dating abuse. However, female attachment anxiety was related to observed male emotional abuse. One explanation for these conflicting findings may be related to the context of the measurement of emotional abuse. For example, male attachment anxiety may be more related to overall emotional abuse because the self-report measure focused on emotional abuse across all romantic inter-

actions. Conversely, female attachment anxiety may be more relevant during times of individual conversation without extraneous distractions (e.g.. during the observed couple interaction). Post hoc examination of the emotional abuse items indicated that two items (bringing up something bad done in the past, saying things to make her angry) were reported more frequently by males, and one item (insults with put-downs) was observed more frequently in females, further strengthening the argument that emotional abuse may have differential effects dependent on the context.

Perhaps what one self-observes versus what another person observes may explain the discrepant effects between attachment anxiety and male emotional abuse. Previous research supports this. For example, males who report more attachment anxiety are more likely to report bringing up a negative history and making comments to make their partner angry (Follingstad et al., 2002). However, males may minimize their own use of insults and put-downs, particularly with an anxiously attached partner, to placate their partner and maintain the relationship. Finally, contrary to Hypothesis 2, after simultaneous consideration of attachment anxiety, neither one's own nor one's partner's attachment avoidance was related to emotional abuse across any measure of emotional dating abuse.

As young adult relationships typically set the stage for later marital relationships, and emotional abuse is a leading risk factor for physical abuse (Riggs \& O'Leary, 1996), understanding factors, such as attachment anxiety, related to emotional abuse is critical for treating and preventing dating abuse. Dating abuse prevention programs implemented in college settings could educate individuals about how their attachment anxiety (e.g., jealousy, fear of abandonment, anger) may relate to emotional abuse within their relationships. For example, attachment anxiety may be confounded by miscommunication about relationship needs (Campbell et al., 2005), suggesting that communication training could be an integral component of dating abuse prevention and intervention efforts. For example. prevention efforts could involve teaching young adults to proactively solve conflicts (e.g., through discussion) before they escalate into aggression (Noonan \& Charles, 2009; Wolfe et al., 2003). In addition, by educating young adults about how to resolve conflict, perceptions that conflict is negative may be reversed allowing for greater mental energy and flexibility to work toward proactive solutions.

\section{LIMITATIONS OF THE CURRENT STUDY AND CONCLUSIONS}

Although this sample includes young adults not enrolled in school ( $9 \%$ of sample), this study was mainly limited to predominantly White college students involved in nonmarital, heterosexual relationships. It is unclear whether these same associations between attachment and emotional dating abuse would exist in a same-aged sample of different cultural and ethnic backgrounds. Future research should replicate these findings with more 
diverse groups of young adults. In addition, it is unclear whether these findings would replicate in both younger adolescent and older, married samples.

A second methodological limitation involves the use of a cross-sectional design. As we present findings demonstrating that attachment drives individual differences in emotional abuse, we are also aware that emotional abuse may in fact drive differences in attachment. Specifically, individuals who exhibit high levels of emotional dating abuse may increase levels of anxiety or avoidant attachment in either themselves or their partner. We cannot completely rule out that the relationship is not related to methodology or a third variable that is related to both. Although we could not address this directional problem, we anticipate that future research using longitudinal designs may help clarify the direction of the relationship. Finally, the use of only four items to measure observed emotional abuse is a limit because these items may only represent a subset of potential emotional abuse items. Furthermore, the interrater reliability of some of these items were less than optimal; however, these may be related to the subtle nature of emotional abuse that may be difficult to observe or masked as a joke.

Despite these limitations, this study provided several contributions to the study of attachment and emotional abuse within romantic relationships. First, we provided further evidence linking attachment anxiety, above and beyond attachment avoidance, to emotional abuse. Furthermore, we established this relationship for both females and males while using a dyadic design to demonstrate that individual histories of behavior may differentially impact interactions within romantic relationships. By incorporating multi-informant. multimethod data, these results suggest that the association between attachment anxiety and emotional abuse may not be a method artifact (i.e., occurring because the same individual completed two questionnaires). Both female and male attachment anxiety was related to female emotional abuse regardless of the methodology. For females, it seems their use of emotional dating abuse is both a function of their own and their partner's attachment, whereas for males, this seems to be primarily a function of their own attachment style.

\section{REFERENCES}

Berger, L. E., Jodl, K. M., Allen, J. P.. McElhaney, K. B., \& Kuperminc, G. P. (2005). When adolescents disagree with others about their symptoms: Differences in attachment organization as an explanation of discrepancies between adolescent, parent, and peer reports of behavior problems. Development and Psychopathology, 17. 509-528. http://dx.doi.org/10.1017/ S0954579405050248

Bond, S. B.. \& Bond. M. (2004). Attachment styles and violence within couples. Journal of Nervous and Mental Disease, 192, 857-863. http://dx.doi.org/10.1097/01.nmd.0000146879.33957.ec

Bookwala, J., \& Zdaniuk, B. (1998). Adult attachment styles and aggressive behavior within dating relationships. Journal of Social and Personal Relationships. 15. 175-190. http://dx.doi .org/10.1177/0265407598152003

Bowlby, J. (1973). Attachment and loss: Volume II: Separation anxiety and anger. New York. NY: Basic Books.

Brennan, K. A., Clark, C. L., \& Shaver, P. R. (1998). Self-report measurement of adult attachment: An integrative overview. In J. A. Simpson \& W. S. Rholes (Eds.), Attachment theory and close relationships (pp. 46-76). New York, NY: Guilford Press.

Campbell, L., Simpson, J. A., Boldry, J., \& Kashy, D. A. (2005). Perceptions of conflict and support in romantic relationships: The role of attachment anxiety. Journal of Personality and Social Psychology, 88, 510-531. http://dx.doi.org/10.1037/0022-3514.88.3.510 
Centers for Disease Control and Prevention. (2014). Understanding teen dating violence: Fact sheet. Atlanta, GA: National Center for Injury Prevention, Centers for Disease Control and Prevention. Retrieved from http://www.cdc.gov/violenceprevention/pdf/teen-dating-violence2014-a.pdf

Cooper, C. R., \& Grotevant, H. D. (1987). Gender issues in the interface of family experience and adolescents' friendship and dating identity. Journal of Youth and Adolescence, 16, 247-264. http://dx.doi.org/10.1007/BF02139093

Doumas, D. M., Pearson, C. L., Elgin, J. E., \& McKinley, L. L. (2008). Adult attachment as a risk factor for intimate partner violence: The "mispairing" of partners' attachment styles. Journal of Interpersonal Violence, 23, 616-634. http://dx.doi.org/10.1177/0886260507313526

Dutton, D. G., Saunders, K., Starzomski, A., \& Bartholomew, K. (1994). Intimacy-anger and insecure attachment as precursors of abuse in intimate relationships. Journal of Applied Social Psychology, 24, 1367-1386. http://dx.doi.org/10.1111/j.1559-1816.1994.tb01554.x

Follingstad, D. R., Bradley, R. G., Helff, C. M., \& Laughlin. J. E. (2002). A model for predicting dating violence: Anxious attachment, angry temperament, and need for relationship control. Violence and Victims, 17, 35-47. http://dx.doi.org/10.1891/vivi.17.1.35.33639

Fraley. R. C.. \& Davis, K. E. (1997). Attachment formation and transfer in young adults' close friendships and romantic relationships. Personal Relationships, 4, 131-144. http://dx.doi . org/10.1111/j.1475-6811.1997.tb00135.x

Fraley, R. C.. Waller, N. G., \& Brennan, K. A. (2000). An item response theory analysis of self-report measures of adult attachment. Journal of Personality and Social Psychology, 78, 350-365. http://dx.doi.org/10.1037/0022-3514.78.2.350

Halpern, C. T., Oslak, S. G., Young, M. L., Martin, S. L., \& Kupper, L. L. (2001). Partner violence among adolescents in opposite-sex romantic relationships: Findings from the National Longitudinal Study of Adolescent Health. American Journal of Public Health. 91, 1679-1685. http://dx.doi.org/10.2105/AJPH.91.10.1679

Heyman, R. E. (2001). Observation of couple conflicts: Clinical assessment applications, stubborn truths, and shaky foundations. Psychological Assessment, 13, 5-35. http://dx.doi .org/10.1037/1040-3590.13.1.5

Kenny, D. A. (1996). Models of non-independence in dyadic research. Journal of Social and Personal Relationships, 13, 279-294. http://dx.doi.org/10.1177/0265407596132007

Kenny, D. A., Kashy, D. A., \& Cook, W. L. (2006). Dyadic data analysis. New York, NY: Guilford Press.

Kesner, J. E., \& McKenry, P. C. (1998). The role of childhood attachment factors in predicting male violence toward female intimates. Journal of Family Violence, 13. 417-432. http://dx.doi .org/10.1023/A:1022879304255

Kuijpers, K. F., van der Knaap, L. M., \& Winkel, F. W. (2012). Risk of revictimization of intimate partner violence: The role of attachment, anger and violent behavior of the victim. Journal of Family Violence, 27, 33-44. http://dx.doi.org/10.1007/s10896-011-9399-8

Lafontaine, M.-F., \& Lussier, Y. (2005). Does anger towards the partner mediate and moderate the link between romantic attachment and intimate violence? Journal of Family Violence, 20. 349-361. http://dx.doi.org/10.1007/s10896-005-7797-5

Lawson. D. M.. \& Brossart. D. (2009). Attachment, interpersonal problems, and treatment outcomes in group therapy for partner violent men. Psychology of Men and Masculinity, 10, 288-301. http://dx.doi.org/10.1037/a0017043

Lawson. D. M., \& Malnar. S. G. (2011). Interpersonal problems as a mediator between attachment and intimate partner violence. Journal of Family Violence, 26, 421-430. http://dx.doi .org/10.1007/s10896-011-9376-2

Margolin, G.. Oliver, P. H.. Gordis. E. B.. O'Hearn. H. G.. Medina. A. M., Ghosh, C. M., \& Morland, L. (1998). The nuts and bolts of behavioral observation of marital and family interaction. Clinical Child and Family Psychology Review, I, 195-213. http://dx.doi.org/10.1023/A: 1022608117322 
Markham-Cox. M. (1991). Marital and parent-child relationships study. Unpublished manuscript. University of North Carolina, Chapel Hill.

Miga. E. M., Hare, A., Allen. J. P., \& Manning. N. (2010). The relation of insecure attachment states of mind and romantic attachment styles to adolescent aggression in romantic relationships. Attachment \& Human Development, 12, 463-481. http://dx.doi.org/10.1080/14616734. 2010.501971

Mikulincer, M., \& Florian, V. (1998). The relationship between adult attachment styles and emotional and cognitive reactions to stressful events. In J. A. Simpson \& W. S. Rholes (Eds.), Attachment theory and close relationships (pp. 143-165). New York. NY: Guilford Press.

Mikulincer, M, \& Shaver, P. R. (2007). Attachment in adulthood: Structure, dynamics, and change. New York, NY: Guilford Press.

Muthén, L. K.. \& Muthén, B. O. (2014). Mplus: Statistical analysis with latent variables (User's Guide). Los Angeles, CA: Author.

Noonan. R. K.. \& Charles, D. (2009). Developing teen dating violence prevention strategies: Formative research with middle school youth. Violence Against Women, 15, 1087-1 105. http:// dx.doi.org/10.1177/1077801209340761

O'Leary. K. D., \& Smith Slep. A. M. (2003). A dyadic longitudinal model of adolescent dating aggression. Journal of Clinical Child and Adolescent Psychology, 32, 314-327. http://dx.doi .org/10.1207/S15374424JCCP3203_01

Orcutt. H. K., Garcia, M., \& Pickett. S. M. (2005). Female-perpetrated intimate partner violence and romantic attachment style in a college student sample. Violence and Victims, 20, 287-302. http://dx.doi.org/10.1891/vivi.20.3.287

Rathus, J. H., \& Feindler, E. L. (2004). Assessment of partner violence: A handbook for researchers and practitioners. Washington, DC: American Psychological Association.

Riggs. S. A.. \& Kaminski. P. (2010). Childhood emotional abuse. adult attachment, and depression as predictors of relational adjustment and psychological aggression. Journal of Aggression, Maltreatment \& Trauma, 19.75-104. http://dx.doi.org/10.1080/10926770903475976

Riggs, D. S., \& O'Leary, K. D. (1996). Aggression between heterosexual dating partners: An examination of a causal model of courtship aggression. Journal of Interpersonal Violence, 11 , 519-540. http://dx.doi.org/10.1177/088626096011004005

Roudsari, B. S., Leahy, M. M., \& Walters, S. T. (2009). Correlates of dating violence among male and female heavy-drinking college students. Journal of Interpersonal Violence, 24, 1892-1905. http://dx.doi.org/10.1177/0886260508325492

Shorey, R. C., Cornelius, T. L., \& Bell, K. M. (2008). A critical review of theoretical frameworks for dating violence: Comparing the dating and marital fields. Aggression and Violent Behavior, 13. 185-194. http://dx.doi.org/10.1016/j.avb.2008.03.003

Shorey, R. C., Rhatigan, D. L., Fite, P. J., \& Stuart, G. L. (2011). Dating violence victimization and alcohol problems: An examination of the stress-buffering hypothesis for perceived support. Partner Abuse, 2, 31-45. http://dx.doi.org/10.1891/1946-6560.2.1.31

Shorey, R. C., Sherman, A. E., Kivisto, A. J., Elkins, S. R., Rhatigan, D. L., \& Moore, T. M. (2011). Gender differences in depression and anxiety among victims of intimate partner violence: The moderating effect of shame proneness. Journal of Interpersonal Violence, 26, 1834-1850. http://dx.doi.org/10.1177/0886260510372949

Shulman, S. (2003). Conflict and negotiation in adolescent romantic relationships. In P. Florsheim (Ed.), Adolescent romantic relations and sexual behavior: Theory, research, and practical implications (pp. 109-135). Mahwah. NJ: Lawrence Erlbaum Associates.

Simon, V. A.. Kobielski, S. J., \& Martin, S. (2008). Conflict beliefs, goals, and behavior in romantic relationships during late adolescence. Journal of Youth and Adolescence, 37, 324-335. http:// dx.doi.org/10.1007/s10964-007-9264-5

Sroufe, L. A., \& Fleeson, J. (1986). Attachment and the construction of relationships. In W. Hartup \& Z. Rubin (Eds.), Relationships and development. Hillsdale. NJ: Lawrence Erlbaum Associates. 
Turner, L. A.. \& Langhinrichsen-Rohling, J. (2011). Attachment, relationship beliefs, and partnerspecific assertiveness and psychological aggression among college students. Partner Abuse, 2, 387-403. http://dx.doi.org/10.1891/1946-6560.2.4.387

van Dulmen, M. H., \& Goncy, E. A. (2010). Extending the actor-partner interdependence model to include cross-informant data. Journal of Adolescence, 33, 869-877. http://dx.doi.org/10.1016/j .adolescence.2010.07.002

van Dulmen, M. H., Mata, A. D.. \& Klipfel, K. M. (2012). Enhancing the assessment of verbal aggression through observational methodology. Journal of Interpersonal Violence, 27, 812-823. http://dx.doi.org/10.1177/0886260511423251

Wolfe, D. A., Scott, K., Reitzel-Jaffe, D., Wekerle, C., Grasley, C., \& Straatman, A. L. (2001). Development and validation of the Conflict in Adolescent Dating Relationships Inventory. Psychological Assessment, 13, 277-293. http://dx.doi.org/10.1037/1040-3590.13.2.277

Wolfe, D. A., Wekerle, C., Scott, K., Straatman, A. L., Grasley, C., \& Reitzel-Jaffe, D. (2003). Dating violence prevention with at-risk youth: A controlled outcome evaluation. Journal of Consulting and Clinical Psychology, 71, 279-291. http://dx.doi.org/10.1037/0022-006X.71.2.279

Acknowledgments. Portions of this article were previously presented at the 2010 Society for Research in Adolescence Conference in Philadelphia, Pennsylvania. This project was partially funded by the Center of the Treatment and Study of Traumatic Stress (Summa Health Systems/Kent State University).

Correspondence regarding this article should be directed to Elizabeth A. Goncy, PhD, Virginia Commonwealth University, Department of Psychology, P.O. Box 842018, Richmond, VA 232842018. E-mail: egoncy@vcu.edu 